\title{
Preparation of Ultrahigh Potential Gradient of ZnO Varistors by Rare-Earth Doping and Low-Temperature Sintering
}

\author{
Lei Ke, ${ }^{1}$ Ming $\mathrm{Hu}^{2}$ and Xueming $\mathrm{Ma}^{3}$ \\ ${ }^{1}$ Department of Mathematics and Physics, Shanghai Dianji University, Shanghai 201306, China \\ ${ }^{2}$ World Premier International Research Center for Materials Nanoarchitectonics, National Institute for Materials Science, \\ Ibaraki 305-0044, Japan \\ ${ }^{3}$ State Key Laboratory of Precision Spectroscopy, East China Normal University, Shanghai 200241, China
}

Correspondence should be addressed to Lei Ke; kelei.sdju@gmail.com

Received 9 December 2012; Accepted 4 January 2013

Academic Editor: Pawan K. Kahol

Copyright (C) 2013 Lei Ke et al. This is an open access article distributed under the Creative Commons Attribution License, which permits unrestricted use, distribution, and reproduction in any medium, provided the original work is properly cited.

The effects of rare-earth doping and low-temperature sintering on electrical properties of $\mathrm{ZnO}$ varistors were investigated. The potential gradient $\left(E_{1 \mathrm{~mA}}\right)$ of the $\mathrm{ZnO}$ varistors increased significantly to $2247.2 \mathrm{~V} / \mathrm{mm}$ after doping $0.08 \mathrm{~mol} \%$ of $\mathrm{Y}_{2} \mathrm{O}_{3}$ and sintering at $800^{\circ} \mathrm{C}$ for $2 \mathrm{~h}$. The notable decrease of the grain size with the given experimental conditions was the origin for the increase in $E_{1 \mathrm{~mA}}$. During the process of high-temperature sintering, both the oxygen at the grain boundary interface and the neutralisation of the ions on the depletion layer were directly reduced, which caused the weight loss and the internal derangement of double Schottky barriers.

\section{Introduction}

ZnO-based varistors are ceramic resistor devices, which have been widely used in voltage stabilization, transient surge protection in electronic circuits and electrical power systems. They exhibit excellent nonlinear current-voltage ( $I$ $V)$ characteristics described by the relation $J=K E^{\alpha}$, where $J$ is the electrical current density, $E$ is the potential gradient, $\alpha$ is the nonlinear coefficient, and $K$ is a constant that depends on the microstructure $[1,2]$.

Numerous researchers have studied the effects of processing and microstructure on electrical conduction in $\mathrm{ZnO}$ varistors [3-5]. The nonlinear current-voltage characteristic results from the formation of double Schottky type electrostatic barriers at the grain boundaries with characteristic voltage drops of 2-3 V per grain boundary [6]. The increase in conductivity has been attributed to the mechanism of depletion layer breakdown or electron tunneling, which is due to the lowering of the electrostatic barriers [7].

Most previous work on fabrication of $\mathrm{ZnO}$ varistors has based on traditional raw materials, which contain zinc oxide mixed with small amounts of other oxides. The samples are sintered at a high temperature about $1200^{\circ} \mathrm{C}[8,9]$.
For the fabrication of high potential gradient varistors, one main method is to decrease the grain size [10]. However, the elevated temperature sintering process accelerates the growth of grain size. In order to reduce grain growth and maintain the high-field properties, rare-earth doping and low-temperature sintering are adopted. A lower temperature reduces the cost and is easier to be realized. The objective of this paper is to investigate the electrical properties of samples produced by this process, especially the potential gradient.

\section{Experimental}

Reagent-grade raw materials were used in proportions of $(96.5-X) \mathrm{mol} \% \mathrm{ZnO}+0.7 \mathrm{~mol} \% \mathrm{Bi}_{2} \mathrm{O}_{3}+1.0 \mathrm{~mol} \% \mathrm{Sb}_{2} \mathrm{O}_{3}+$ $0.5 \mathrm{~mol} \% \mathrm{Cr}_{2} \mathrm{O}_{3}+0.8 \mathrm{~mol} \% \mathrm{Co}_{2} \mathrm{O}_{3}+0.5 \mathrm{~mol} \% \mathrm{MnO}_{2}+X$ $\mathrm{mol} \% \mathrm{Y}_{2} \mathrm{O}_{3}$, with $X$ equal to 0 or 0.08 . Instead of grinding for more hours with a conventional ball milling, raw materials were mixed by high-energy ball milling with stainless steel balls and ethanol in a nylon bottle for $5 \mathrm{~h}$ at $500 \mathrm{rpm}$. The mixture was dried at $120^{\circ} \mathrm{C}$ for $2 \mathrm{~h}$ and pulverized using an agate mortar/pestle. The powder samples were mixed with few drops of a binder addition of $2 \mathrm{wt} \%$ polyvinyl alcohol (PVA) and uniaxially pressed into discs of $10 \mathrm{~mm}$ in diameter 
TABLE 1: Relative density of samples with different doping concentrations and sintering temperatures.

\begin{tabular}{lccc}
\hline Groups & $\begin{array}{c}\text { Doping } \\
\text { concentration of } \\
\mathrm{Y}_{2} \mathrm{O}_{3}(\mathrm{~mol} \%)\end{array}$ & $\begin{array}{c}\text { Sintering } \\
\text { temperature } \\
\left({ }^{\circ} \mathrm{C}\right)\end{array}$ & $\begin{array}{c}\text { Relative density } \\
(\%)\end{array}$ \\
\hline Sample 1 & 0.00 & 1200 & 96.37 \\
Sample 2 & 0.08 & 1200 & 96.31 \\
Sample 3 & 0.00 & 800 & 98.70 \\
Sample 4 & 0.08 & 800 & 98.03 \\
\hline
\end{tabular}

and $1 \mathrm{~mm}$ in thickness under $150 \mathrm{Mpa}$ pressure. The green pellets were, respectively, sintered at $800^{\circ} \mathrm{C}$ and $1200^{\circ} \mathrm{C}$ for $2 \mathrm{~h}$. The densities of the pellets were measured by Archimedes method. Silver paste was coated on both faces of the pellets and the ohmic contact of electrodes was formed by heating at $600^{\circ} \mathrm{C}$ for 15 minutes. All samples were divided into four groups for investigation, as shown in Table 1.

The crystalline phases were identified by an X-ray diffractometry (XRD, D/max $2550 \mathrm{~V}$ ) using a $\mathrm{CuK}_{\alpha}$ radiation. The surface microstructure was examined by a scanning electron microscope (SEM, JSM-5610LV). The average grain size $(D)$ was determined by the measurement on the micrographs with the linear intercept method using the following expression $[11,12]$ :

$$
D=\frac{1.56 L}{M N},
$$

where $L$ is the random line length on the micrograph, $M$ is the magnification of the micrograph, and $N$ is the number of the grain boundaries intercepted by lines. The electrical properties of varistors were measured using a DC parameter instrument (CJ1001). The breakdown voltage $\left(U_{1 \mathrm{~mA}}\right)$ was measured at the current density of $1.0 \mathrm{~mA} / \mathrm{cm}^{2}$ and the potential gradient $\left(E_{1 \mathrm{~mA}}\right)$ was obtained by $E_{1 \mathrm{~mA}}=U_{1 \mathrm{~mA}} / d$, where $d$ is the thickness of sample. The leakage current $\left(I_{L}\right)$ was measured at the electrical field of $0.75 U_{1 \mathrm{~mA}}$ and the nonlinear coefficient $(\alpha)$ was determined in the range of $1.0 \mathrm{~mA} / \mathrm{cm}^{2}$ to $10 \mathrm{~mA} / \mathrm{cm}^{2}$ in current density, according to the expression of $\alpha=1 /\left(\log E_{10 \mathrm{~mA}}-\log E_{1 \mathrm{~mA}}\right)$. It also contained a built-in $1400 \mathrm{kV}$ DC power supply so as to describe the $I-V$ property.

\section{Discussion of Results}

Figure 1 shows the phase composition of four samples. It is observed that $\mathrm{ZnO}$ is the main phase and $\mathrm{Zn}_{7} \mathrm{Sb}_{2} \mathrm{O}_{12}$ is the secondary phase in all the systems. However, one can also observe the presence of bismuth-rich phase for Sample 3 and Sample 4, and $\mathrm{Y}_{2} \mathrm{O}_{3}$ phase for Sample 4 only. This indicates that the additive $\mathrm{Y}_{2} \mathrm{O}_{3}$ after sintering at $1200^{\circ} \mathrm{C}$ is forming a solid solution with $\mathrm{ZnO}$ according to the following equation:

$$
\mathrm{Y}_{2} \mathrm{O}_{3} \stackrel{\mathrm{ZnO}}{\longrightarrow} 2 \mathrm{Y}_{\mathrm{Zn}}^{\circ}+\mathrm{V}_{\mathrm{Zn}}^{\prime \prime}+2 \mathrm{O}_{\mathrm{O}}^{\times}+\frac{1}{2} \mathrm{O}_{2} \uparrow
$$

As indicated in (2), the formation of solid solution in the $\mathrm{ZnO}$ lattices should increase the zinc vacancy concentration.

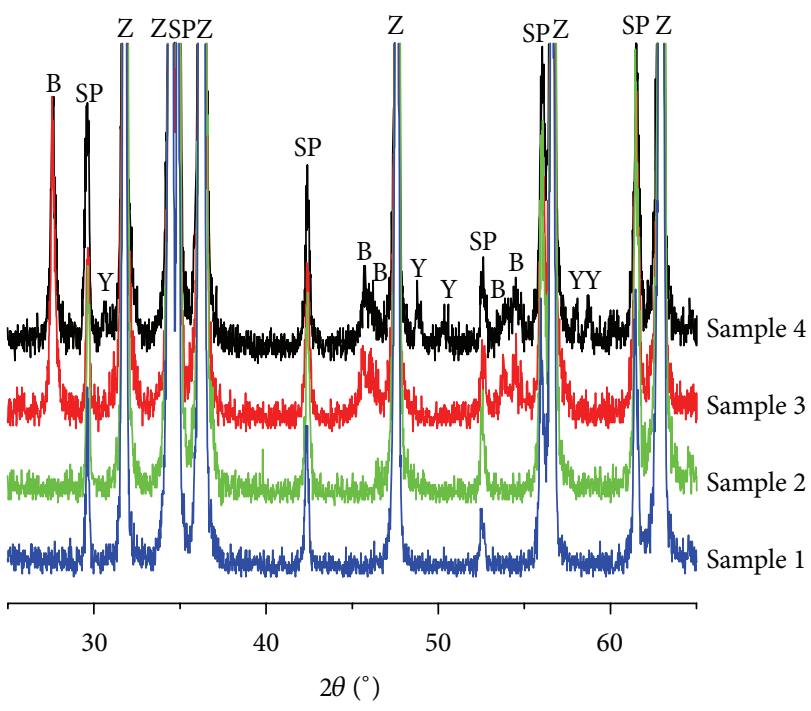

$$
\begin{array}{ll}
\mathrm{Z}: \mathrm{ZnO} \text { phase } & \mathrm{B}: \mathrm{Bi}_{2} \mathrm{O}_{3} \text { phase } \\
\text { SP: } \mathrm{Zn}_{7} \mathrm{Sb}_{2} \mathrm{O}_{12} \text { phase } & \mathrm{Y}_{2} \mathrm{Y}_{2} \mathrm{O}_{3} \text { phase }
\end{array}
$$

FIGURE 1: XRD data of the four samples.

These defects restrain the diffusion of electron through the lattices, decreasing $\alpha$ of the ceramic in a certain extent. The disappearance of bismuth-rich phase indicates that the $\mathrm{Bi}_{2} \mathrm{O}_{3}$ phase is bounded into other phases or volatilized badly at the sintering temperature of $1200^{\circ} \mathrm{C}$, which is unfavorable to the nonlinearity. The decrease of relative density results also from the volatilization of $\mathrm{Bi}_{2} \mathrm{O}_{3}$ (see Table 1).

Microstructural observations show a significant influence of $\mathrm{Y}_{2} \mathrm{O}_{3}$ doping and sintering temperatures on the morphology of the $\mathrm{ZnO}$ grains and the distribution of the grain size. The $\mathrm{ZnO}$ grain size has an obvious decrease from $1.602 \mu \mathrm{m}$ to $1.145 \mu \mathrm{m}$ with $\mathrm{Y}_{2} \mathrm{O}_{3}$ doping (see Figures 2(c) and 2(d)) and from $3.377 \mu \mathrm{m}$ to $1.145 \mu \mathrm{m}$ with low-temperature sintering (see Figures 2(b) and 2(d)). Comparing with the conventional $\mathrm{ZnO}$ varistors $[2,8]$, the grain size of Sample 4 has been reduced by at least $50 \%$. The temperature at which the liquid phase occurs is about $740^{\circ} \mathrm{C}$. Much higher above this temperature, such as $1200^{\circ} \mathrm{C}$, exaggerated grain growth occurs. Exaggerated grain growth results in a bimodal grain size distribution, with the small grains among the huge ones. Due to the exaggerated grain growth and the volatilization of $\mathrm{Bi}_{2} \mathrm{O}_{3}, \mathrm{Y}_{2} \mathrm{O}_{3}$ doping nearly makes no difference on the microstructure of $\mathrm{ZnO}$ varistors during the high sinter temperature (see Figures 2(a) and 2(b)). The micrographs in Figure 2 also witness that the obtained Sample 4 is nanograined and contains the very developed free surfaces as well as grain boundaries. It has been demonstrated recently that the physical properties of nanograined $\mathrm{ZnO}$, especially doped one, strongly depend on the presence of defects like grain boundaries and on the presence of amorphous surficial and intergranular layers $[13,14]$. The crystalline $\mathrm{ZnO}$ grains of Sample 4 do not directly contact each other and are completely surrounded by a thin layer of material such as amorphous intergranular phase. It forms a kind of continuous foam-like network, where the amorphous intergranular 


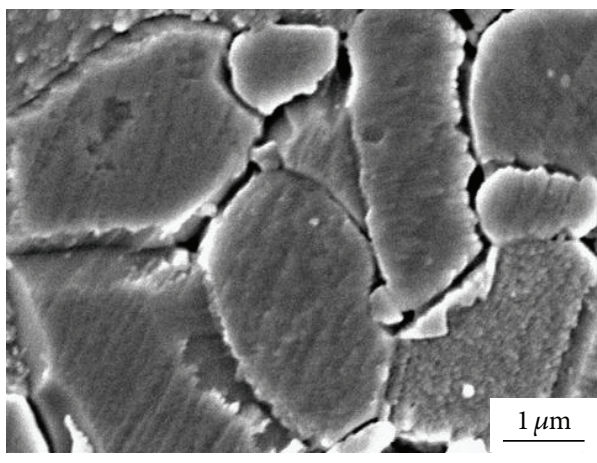

(a)

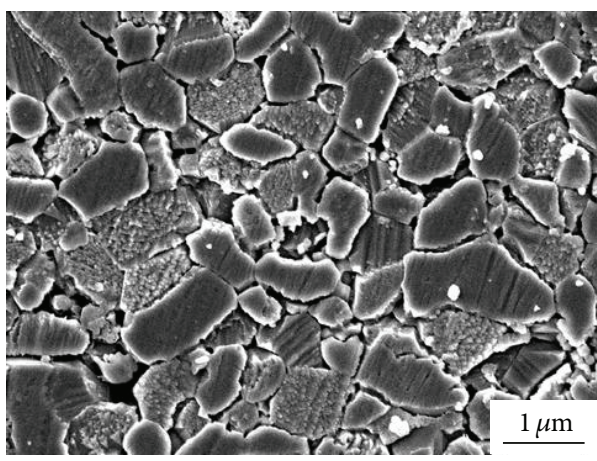

(c)

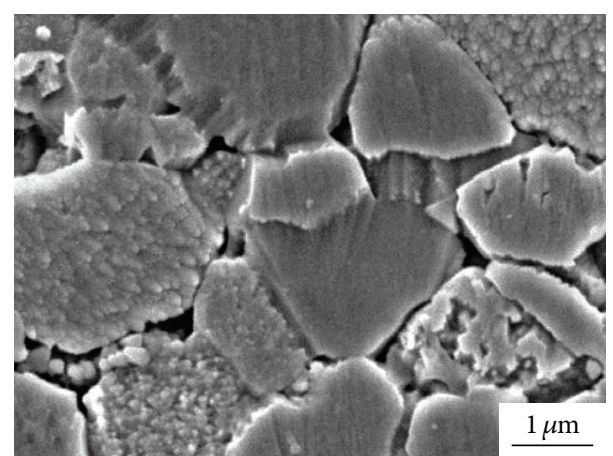

(b)

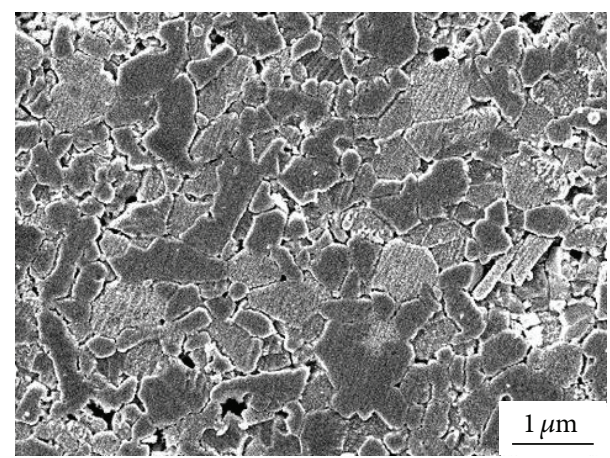

(d)

Figure 2: SEM images for (a) Sample 1, (b) Sample 2, (c) Sample 3, and (d) Sample 4.

TABLE 2: $I_{L}, E_{1 \mathrm{~mA}}$, and $\alpha$ for the four samples.

\begin{tabular}{lccc}
\hline Groups & $I_{L}(\mu \mathrm{A})$ & $E_{1 \mathrm{~mA}}(\mathrm{~V} / \mathrm{mm})$ & $\alpha$ \\
\hline Sample 1 & 396 & 114.7 & 3.0 \\
Sample 2 & 355 & 193.7 & 3.6 \\
Sample 3 & 16.4 & 1626.1 & 13.8 \\
Sample 4 & 9.1 & 2247.2 & 23.0 \\
\hline
\end{tabular}

phase amount could be increased by the decrease in grain size.

The electrical characterization of these samples normalized in potential gradient $E(\mathrm{~V} / \mathrm{mm})$ as a function of current density $J\left(\mu \mathrm{A} / \mathrm{mm}^{2}\right)$ is shown in Figure 3. The values of $I_{L}, E_{1 \mathrm{~mA}}$, and $\alpha$ are presented in Table 2. Comparing with the other three samples, Sample 4 has the highest $E_{1 \mathrm{~mA}}$ $(2247.2 \mathrm{~V} / \mathrm{mm})$ and $\alpha(23.0)$. The $E_{1 \mathrm{~mA}}$ value of most of the existing commercial $\mathrm{ZnO}$ varistors is below $2000 \mathrm{~V} / \mathrm{mm}$ [3]. The potential gradient of Sample 4 has been increased at least $12 \%$. Increasing the sintering temperature causes the grains to grow, and the electrical active grain boundaries decrease with the volatilization of $\mathrm{Bi}_{2} \mathrm{O}_{3}$. A sharp rise in $I_{L}$, after sintering at $1200^{\circ} \mathrm{C}$, is attributed to the lowering of the grain boundary barrier height with the disappear of bismuth-rich phase.

Some early researches about $\mathrm{ZnO}$-based varistors report that the best nonlinear behavior is achieved between $1200^{\circ} \mathrm{C}$ and $1300^{\circ} \mathrm{C}$. However, in the specific case of our varistors, the change in $\alpha$ with the sintering temperature, as shown

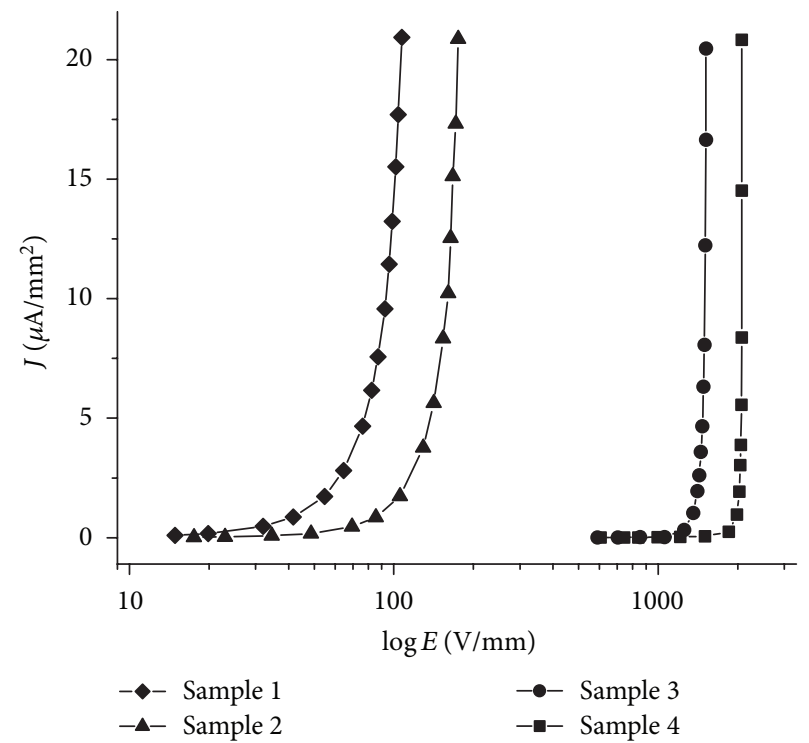

FIgURE 3: Partial $I-V$ characteristics for the four samples.

in Figure 4, is related to the microstructural modifications associated with the reactions that occur during the liquid phase sintering. Higher sintering temperature makes the reactions more adequately, except the largely evaporation process of $\mathrm{Bi}_{2} \mathrm{O}_{3}$. In the present varistor systems where no bismuth-rich phase is observed in Sample 1 and Sample 2, 


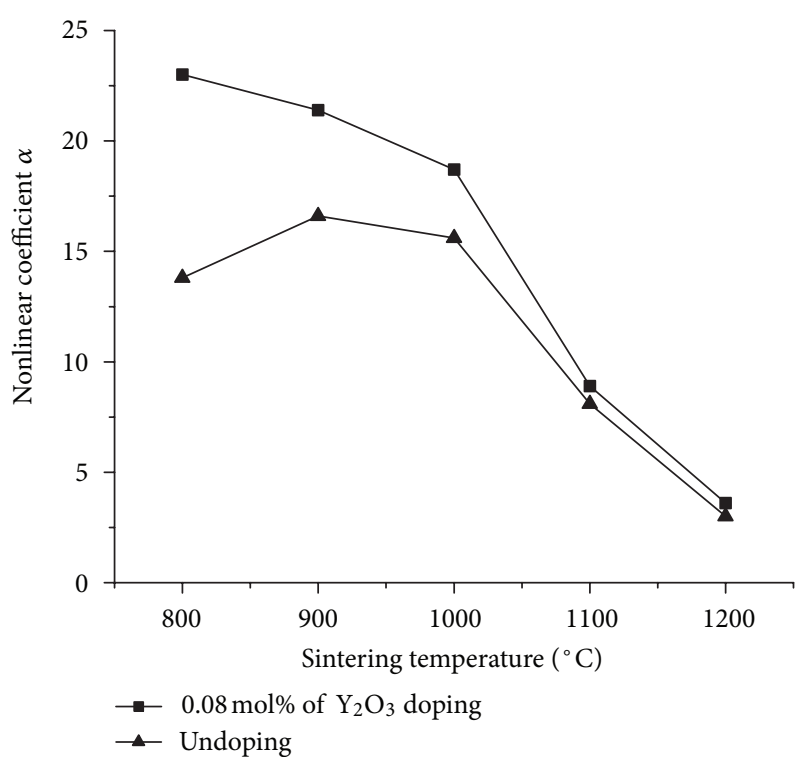

FIGURE 4: Evolution of the nonlinear coefficient $\alpha$ as a function of sintering temperature.

this dependence would be related to the high-energy ball milling in the early period of experiment and the pinning effect of $\mathrm{Y}_{2} \mathrm{O}_{3}$ during the sintering process. High-energy ball milling induces the grain refinement, and the deliquescent $\mathrm{Y}_{2} \mathrm{O}_{3}$ particles between $\mathrm{ZnO}$ grains restrain the grain growth. Both of these realize the wetting of smaller grains at a relative lower temperature.

On the other hand, the ionic radius of $\mathrm{Y}^{3+}(0.89 \AA \hat{\AA})$ is larger than the ionic radius of $\mathrm{Zn}^{2+}(0.74 \AA$ ) $)$. It is difficult for $\mathrm{Y}^{3+}$ ions to solid dissolve into the grains at a lower temperature $\left(800^{\circ} \mathrm{C}\right) . \mathrm{Y}^{3+}$ ions dissolve at the grain boundaries and exist in the forms of $\mathrm{Y}_{2} \mathrm{O}_{3}$ and/or other two crystal phases of $\mathrm{Bi}_{3} \mathrm{YO}_{6}$ and $\mathrm{Bi}_{19} \mathrm{YO}_{3}[15]$. The equilibrium reactions occurred at the grain boundaries can be written (not observed in our experiment) as

$$
\begin{gathered}
3 \mathrm{Bi}_{2} \mathrm{O}_{3}+\mathrm{Y}_{2} \mathrm{O}_{3} \longrightarrow 2 \mathrm{Bi}_{3} \mathrm{YO}_{6} \\
19 \mathrm{Bi}_{2} \mathrm{O}_{3}+\mathrm{Y}_{2} \mathrm{O}_{3} \longrightarrow 2 \mathrm{Bi}_{19} \mathrm{YO}_{30}
\end{gathered}
$$

The dissolved $\mathrm{Y}^{3+}$ ions have no effect on the lattice structure of $\mathrm{ZnO}$. They form small particles at the edge of the grains and as a result pin the grains to restrict their growth. The decrease of the grain size directly induces the increase in the amount of grain boundaries, subsequently in $E_{1 \mathrm{~mA}}$ and $\alpha$. At a higher temperature $\left(1200^{\circ} \mathrm{C}\right)$, with the volatilization of $\mathrm{Bi}_{2} \mathrm{O}_{3}$, the above-mentioned reaction processes do not occur, however, being substituted by the solid solution reaction according to (2). High sinter temperature makes the solid solution reaction occur easily. $\mathrm{Y}^{3+}$ ions act as acceptor ions, which make the resistance of grains rise, with the given experimental conditions of high-energy ball milling and low-temperature sintering. Additional vacancies $\left(\mathrm{V}_{\mathrm{Zn}}{ }^{\prime \prime}\right)$ are created with $\mathrm{Y}^{3+}$ ions solid dissolved into the $\mathrm{ZnO}$ grains. The volatilization of $\mathrm{Bi}_{2} \mathrm{O}_{3}$ causes the resistance of grain boundaries to decrease. The reduction of differences in resistance between the grain boundaries and the grains accelerates the degeneration in nonlinear of the varistors (see Table 2).

With (2) proceed during the sintering process, more $\mathrm{V}_{\mathrm{Zn}}{ }^{\prime \prime}$ and oxygen appear. The oxygen migrates away along the grain boundaries, which causes a significant rightward progress of (2). The shortage of oxygen makes the reaction occur during the cooling process as follows:

$$
\begin{gathered}
\frac{1}{2} \mathrm{O}_{2}(\mathrm{~g}) \longrightarrow \mathrm{O}_{\mathrm{ad}}^{\times} \\
\mathrm{O}_{\mathrm{ad}}^{\times}+\mathrm{V}_{\mathrm{Zn}}^{\prime \prime} \longrightarrow \mathrm{O}_{\mathrm{ad}}{ }^{\prime \prime}+\mathrm{V}_{\mathrm{Zn}}^{\times}
\end{gathered}
$$

where $\mathrm{O}_{\mathrm{ad}}$ is the adsorbed oxygen at the grain boundaries.

According to the model proposed by Gupta and Carlson [16], $\mathrm{V}_{\mathrm{O}}{ }^{\bullet}, \mathrm{V}_{\mathrm{O}}{ }^{\bullet}, \mathrm{Zn}_{i}{ }^{\bullet}$, and $\mathrm{Zn}_{i}{ }^{\bullet}$ are the primary defects on the depletion layer. The donor levels of $\mathrm{V}_{\mathrm{O}} \cdot$ and $\mathrm{V}_{\mathrm{O}}{ }^{*}$ are at 0.5 and $\sim 2 \mathrm{eV}$ below the conduction band edge of $\mathrm{ZnO}$, it is too large for $\mathrm{O}_{\mathrm{ad}}$ " to enter into the lattices of varistors to form $\mathrm{O}_{\mathrm{O}}$ ". Instead, a charge transfer occurs between the positively charged oxygen vacancy and the negatively charged adsorbed oxygen at the interface:

$$
\mathrm{O}_{\mathrm{ad}}{ }^{\prime \prime}+\mathrm{V}_{\mathrm{O}} \cdot \ddot{\mathrm{O}} \rightarrow \mathrm{V}_{\mathrm{O}}^{\times}+\frac{1}{2} \mathrm{O}_{2} \uparrow
$$

The reactions described above only contain the doubly charged ions, and a similar analogy can be written for the singly charged ions as well. With the loss of oxygen, the neutralisation of the ions on the depletion layer reduces the barrier height of double Schottky barrier and finally decreases the potential gradient of the varistors.

\section{Conclusions}

The $\mathrm{ZnO}$ varistors with ultrahigh potential gradient are prepared by rare-earth doping and low-temperature sintering. The origin for this is the great decrease of grain size. The experimental results indicate that the deliquescent $\mathrm{Y}_{2} \mathrm{O}_{3}$ particles between $\mathrm{ZnO}$ grains during the low-temperature sintering process restrain the grain growth and promote the electrical nonlinear. At a higher temperature, the decrease of potential gradient can be explained by the solid solution of $\mathrm{Y}^{3+}$ ions and the volatilization of $\mathrm{Bi}_{2} \mathrm{O}_{3}$. The adsorbed $\mathrm{O}_{\mathrm{ad}}{ }^{\prime \prime}$ ions at the grain boundaries induce the neutralisation of ions on the depletion layer and cause the barrier lowering, which also have an effect on the electrical properties of the varistors.

\section{Acknowledgments}

The authors gratefully acknowledge the financial support of the National Natural Science Foundation of China (Grants no. 50471045 and no. 10804071), Shanghai Municipal Education Commission Project (Grants no. 12AZ16 and no. 12YZ185), and Shanghai Dianji University Project (Grants no. 11C409). 


\section{References}

[1] M. A. Ashrafa, A. H. Bhuiyanb, M. A. Hakimc et al., "Microstructure and electrical properties of $\mathrm{Ho}_{2} \mathrm{O}_{3}$ doped $\mathrm{Bi}_{2} \mathrm{O}_{3}$-based $\mathrm{ZnO}$ varistor ceramics," Physica $B$, vol. 405, no. 17, pp. 3770-3774, 2010.

[2] T. K. Gupta, "Application of zinc oxide varistors," Journal of the American Ceramic Society, vol. 73, no. 7, pp. 1817-1840, 1990.

[3] S. Shichimiya, M. Yamaguchi, N. Furuse, M. Kobayashi, and S. Ishibe, "Development of advanced arresters for GIS with new zinc-oxide elements," IEEE Transactions on Power Delivery, vol. 13, no. 2, pp. 465-471, 1998.

[4] M. M. Shahrakia, S. A. Shojaeec, M. A. F. Sania et al., "Two-step sintering of $\mathrm{ZnO}$ varistors," Solid State Ionics, vol. 190, no. 1, pp. 99-105, 2011.

[5] E. Savarya, S. Marinela, F. Gascoina et al., "Peculiar effects of microwave sintering on $\mathrm{ZnO}$ based varistors properties," Journal of Alloys and Compounds, vol. 509, no. 21, pp. 6163-6169, 2011.

[6] G. D. Mahan, L. M. Levinson, and H. R. Philipp, "Theory of conduction in ZnO varistors," Journal of Applied Physics, vol. 50, no. 4, pp. 2799-2812, 1979.

[7] K. Eda, "Conduction mechanism of non-Ohmic zinc oxide ceramics," Journal of Applied Physics, vol. 49, no. 5, pp. 29642972, 1978.

[8] M. Peiteado, J. F. Fernández, and A. C. Caballero, "Processing strategies to control grain growth in $\mathrm{ZnO}$ based varistors," Journal of the European Ceramic Society, vol. 25, no. 12, pp. 2999-3003, 2005.

[9] S. T. Kuo and W. H. Tuan, "Grain growth behaviour of $\mathrm{ZnO}$ based multilayer varistors," Journal of the European Ceramic Society, vol. 30, no. 2, pp. 525-530, 2010.

[10] J. He, J. Liu, J. Hu, R. Zeng, and W. Long, "Non-uniform ageing behavior of individual grain boundaries in $\mathrm{ZnO}$ varistor ceramics," Journal of the European Ceramic Society, vol. 31, no. 8, pp. 1451-1456, 2011.

[11] American Society for Metals, Metals Handbook, Volume 8: Metallography, Structures and Phase Diagrams, American Society for Metals, Warrendale, Pa, USA, 8th edition, 1973.

[12] H. O. Toplan and Y. Karakas, "Grain growth in $\mathrm{TiO}_{2}$-added $\mathrm{ZnO}-\mathrm{Bi}_{2} \mathrm{O}_{3}-\mathrm{CoO}-\mathrm{MnO}$ ceramics prepared by chemical processing," Ceramics International, vol. 28, no. 8, pp. 911-915, 2002.

[13] B. B. Straumal, A. A. Mazilkin, S. G. Protasova et al., "Amorphous grain boundary layers in the ferromagnetic nanograined ZnO films," Thin Solid Films, vol. 520, pp. 1192-1194, 2011.

[14] B. B. Straumal, S. G. Protasova, A. A. Mazilkin et al., "Amorphous interlayers between crystalline grains in ferromagnetic ZnO films," Materials Letters, vol. 71, pp. 21-24, 2012.

[15] Y. Shimizu, F. C. Lin, Y. Takao, and M. Egashira, "Zinc oxide varistor gas sensors: II, effect of chromium(III) oxide and yttrium oxide additives on the hydrogen-sensing properties," Journal of the American Ceramic Society, vol. 81, no. 6, pp. 16331643, 1998.

[16] T. K. Gupta and W. G. Carlson, "A grain-boundary defect model for instability/stability of a $\mathrm{ZnO}$ varistor," Journal of Materials Science, vol. 20, no. 10, pp. 3487-3500, 1985. 

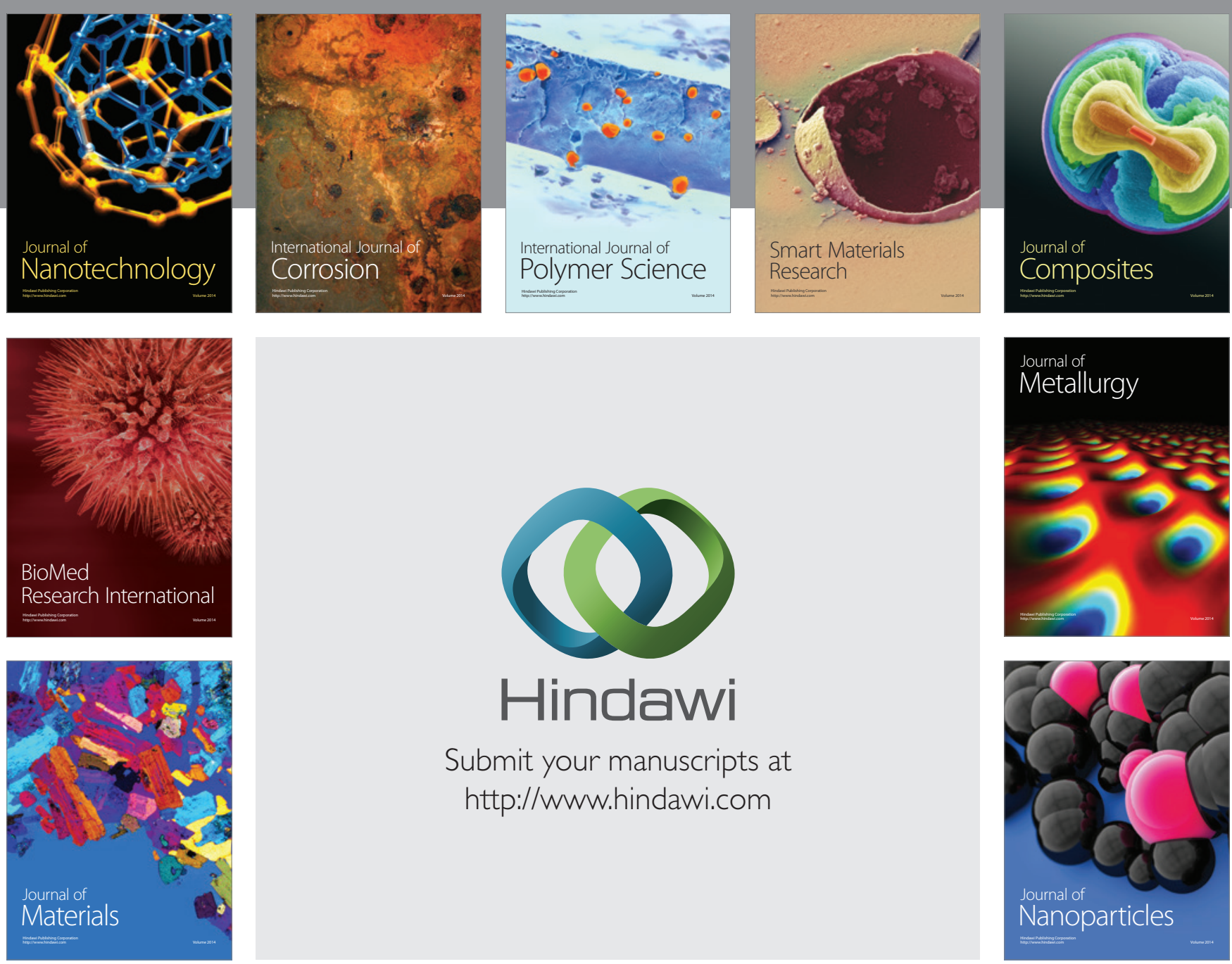

Submit your manuscripts at http://www.hindawi.com
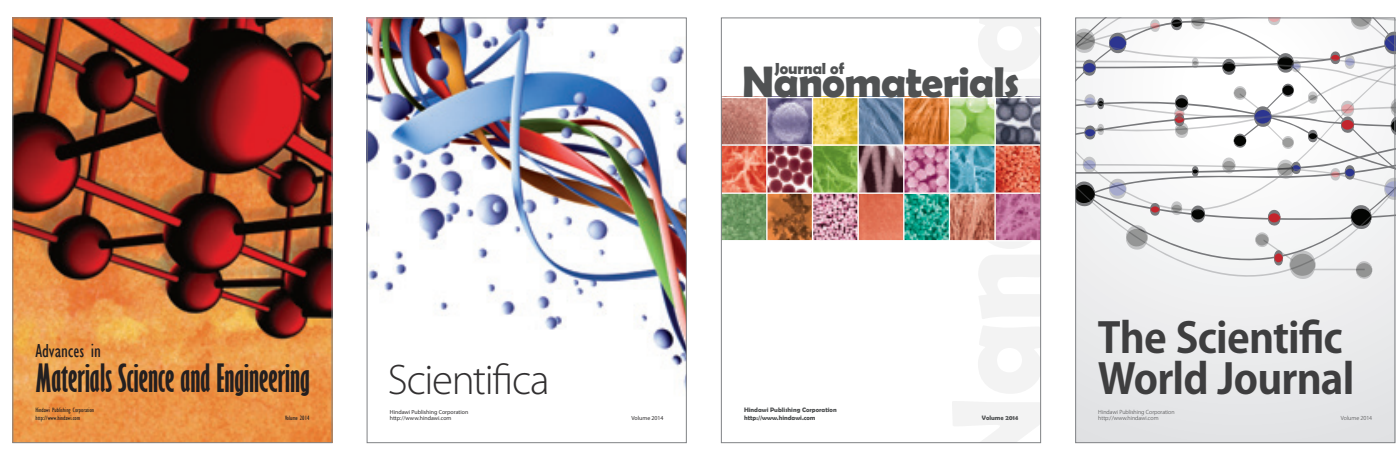

\section{The Scientific World Journal}
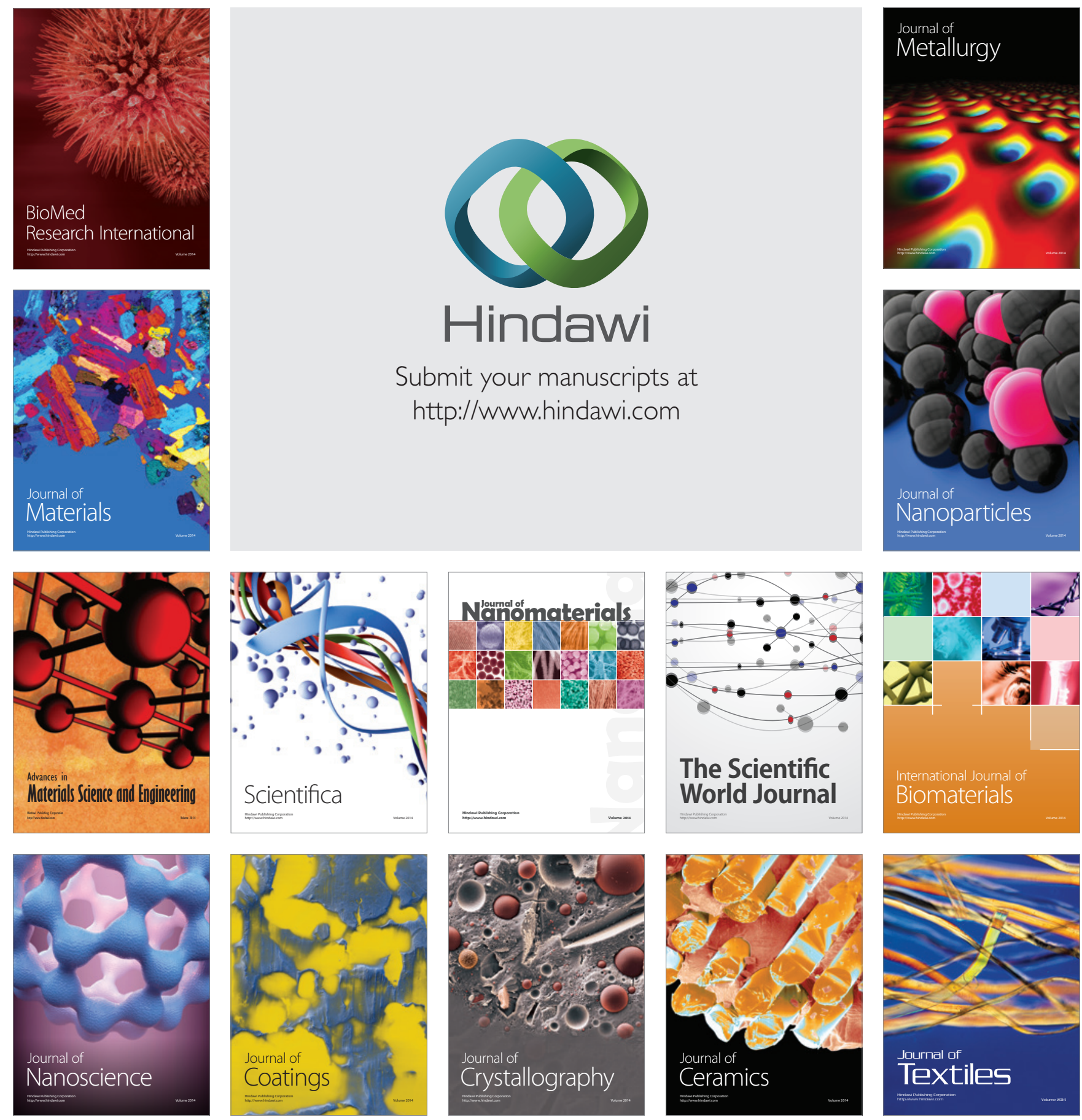